\title{
Research
}

\section{Delayed antibiotic prescribing and associated antibiotic consumption in adults with acute cough}

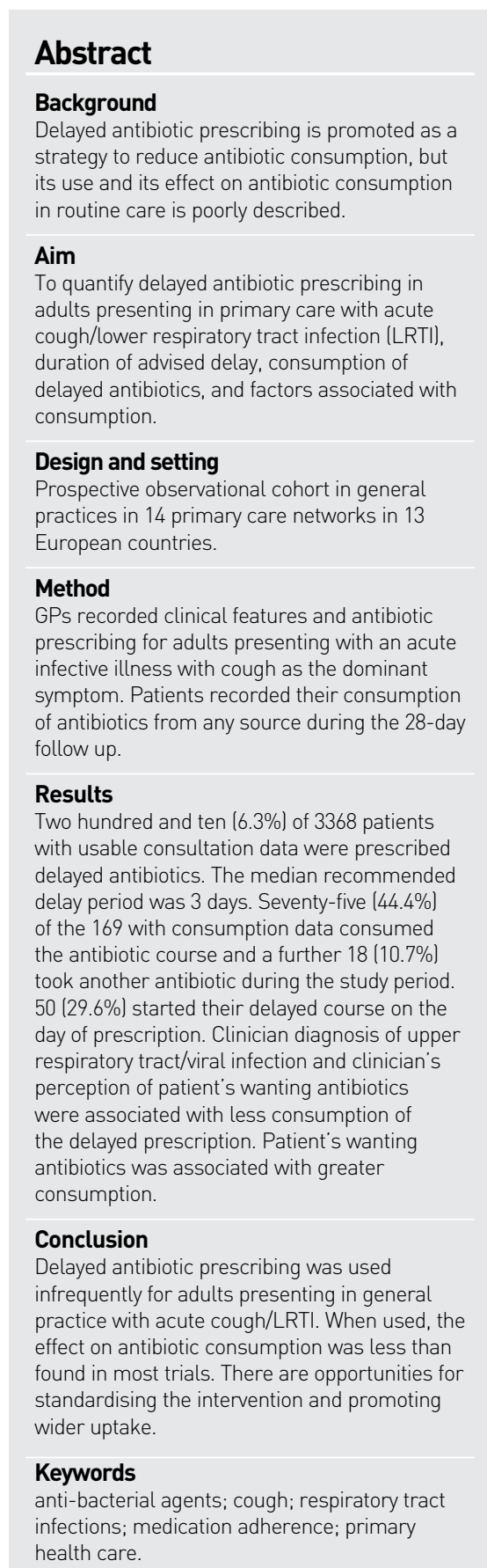

\section{INTRODUCTION}

Concern about the overuse of antibiotics respiratory tract infections,' has led some to recommend the use of a delayed or eferred prescribing approach. ${ }^{2}$ Delaye antibiotic prescribing involves prescribing an antibiotic but advising the patient not to start taking the course unless they deteriorate or fall to improve after a set period. Advocates suggest that in addition delayed prescribing may increase patien, empowerment and satisfaction, avoid medicalisation, reduce reconsultations, and provide a safety net. ${ }^{2-5}$ Trials and systematic reviews of delayed prescribing strategies have demonstrated reductions in the use of antibiotics for patients with cough, acule ollis media, and sore throat. mowever, delayed prescribing may lead to unusd medication leading to use at a date, and lower levels of satisfaction?

Evidence supporting the use of delayed rescribing and recommendations to adopt this strategy have been widely disseminate since the late 1990's. ${ }^{8}$ Reductions in antibiotic use in the UK during the late anelies and early 2000 s have been party prescribing. 3.10 However, there is little

NA Francis, BA, PhD, PGD, MD, MRCGP, senior MD, HonFFPH, director, Cochrane Institute of BSC, research associate, statisticician; J Juttall

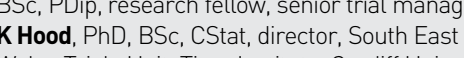
school of Medicine, Cardifft. P L Little, BA, MRCP. MD, FRCGP, FMedSci, professor of primary care
research, Primary Care Medical Group, University Th Southampton School of Medicine, Southampton
TVerheij, MD, PDD, MRCGP, professor of general practice, J Julus Center ror Heatth sciences and
Primary Care, University Medical Center Utrech

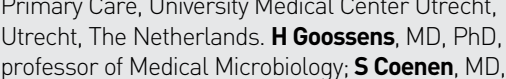

evidence about how frequently this strategy is used in everyday clinical practice, Between $24 \%{ }^{7}$ and $45 \%{ }^{6}$ of patients prescribed antibiotics in trials of delayed prescribing collect their prescriptions, but it is not clear how often patients who are prescribed delayed prescriptions actually take them outside of trial conditions. Describing clinicians uptake of this receiving a delayed prescription and factors that are associated with a decision to use a delayed prescription, will help assess the current impact of this approach, and may identify opportunities for improvement.

In this observational study of acute cough in adults in 14 European primary care networks the study set out to quantify delayed antibiolic prescribing in adults duration if privised delay consumption of delayed antibiotics, and factors associated with consumption.

METHOD

Study design

A prospective observational study was conducted in 14 primary care networks in 13 European countries. The aim was to and outcome of acute cough in primary

PhD, research leader \& senior lecturer; LMM, Niversity of Antwerp, Antwerp. Address for correspondence

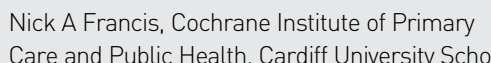
of Medicine, Cardiff, CF14 4YS E-mail: francisnaadcf.ac.uk Submitted: 10 November 2011; Editor's response: 30 March 2012; final acceptance: 10 April 2012 OBritish Journal of General Practice 28 Aug 2012 l) of an abridged version published as: Br J Gen Pract 2012; DOl: 10.3399//jgpp12X654614.

\section{How this fits in}

approach and is recommended in UK

a of this a p. Lith is known about the

practice, the effect it has on antibiotic

sssociated with consumption of a delayed

prescription. This study shows that delayed

nfrequently across European primary care

networks, and when used, was not being

mplemented in line with current evidence.

More than hall of hose preschibed delayed

(a) study period

Care, and the variation between different European countries. More details on this observational GRACE (Genomics to combat Resistance against Antibiotics Community-acquired LRTl in Europe; nnw. grace-Irti.org) study of acute cough have

\section{Participants}

Eligible patients were aged $\geq 18$ years consulting with what the clinician judged to be a new infective illness where an acute or worsened cough was the main or dominan symptom, or had a clinical presentation that suggested a lower respiratory tract and including 28 days. The inclusion criteria were deliberately broad because there is a wide variation in the use of diagnostic terms for respiratory tract infections (RTIs) and the study wanted to capture usual practice. However, clinicians were asked to record their working diagnosis. Participating practices were asked to recruit consecutive November 2006 and from Late January to March 2007.

\section{Data collection}

Cliniclans recorded aspects of patients history, symptoms, comorbidities Idiabetes, chronic lung disease including chronic obstructive pulmonary disease (COPD) and their working diagnosis, whether they thought the patient wanted antibiotics. and their management including antibiotic prescribing decision on a case report form (CRF) at the time of first presenting in primary care. Clinicians recorded whether they prescribed antibiotics or not, and if the antibiotic treatment, whether it was for immediate or delayed use, and if delayed, the advised delay period. Patients were asked to complete a daily symptom diary for 28 days, which included weekly details on antibiotic consumplion, stating which and whether or not it was prescribed. At the start of the diary they were asked if they were expecting their GP to prescribe antibiotics, if they hoped that their GP would prescribe antibiotics, and if they had asked their GP for antibiotics. Those who had indicated that they elther hoped for antibiotics or had asked for antibiotics were A formal power calculation for the
current analyses was not conducted. The original sample size calculation was based on estimating the prevalence of prescribing within each network with a certain degree of Analysis

Descriptives. The proportion of patients prescribed immediate, delayed, and no calculated. For those prescribed delayed antibiotics, the median advised delay period was calculated, overall and by network, and the proportion of patients in each network who were advised to delay for $\geq 7$ days. ${ }^{4}$ Patient reported weekly medication use was categorised as an antibiotic or not medicines taken Ambiguous responses were discussed by the study team and classified or recorded as missing depending on group consensus. The proportion of patients who reported consuming their delayed prescription and the proportion who reported taking another antibiotic at any point in the 4-week follow up period

Regression analysis. The study used a two level hierarchical logistic regression model, with patients nested within clinicians, the consumption of a delayed antibiotic prescription. The study tested variables at a univariate level and included those that were significant at the $10 \%$ level. Variables lage; sex; comorbid illness [at least one of chronic obstructive pulmonary disease $\{C O P D\}$, asthma, other lung disease, heart failure, ischaemic heart disease, other heart disease or diabetes]; and employment status [categorised as: employed, not employed]), advised duration of delay ldichotomised to 


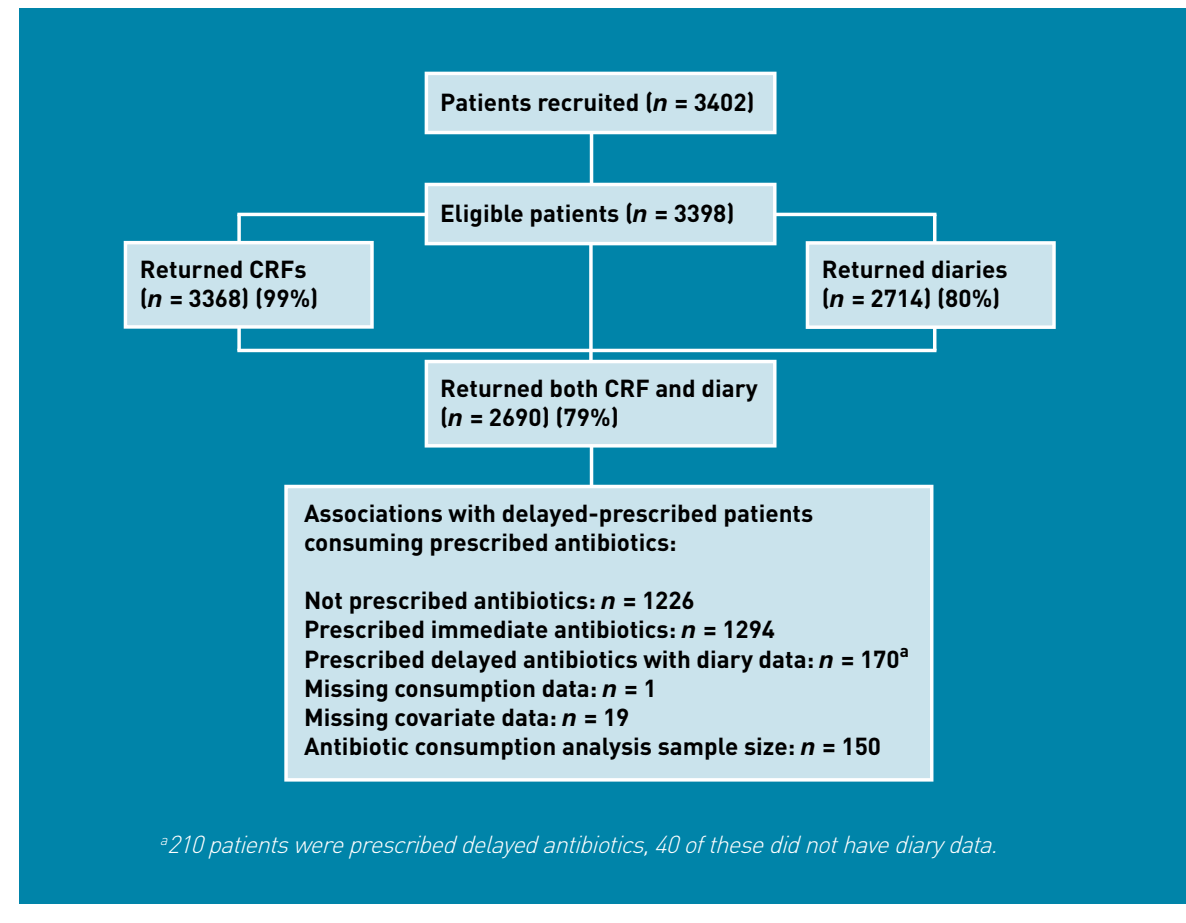

Figure 1. Patient flow diagram

of illness, ${ }^{12}$ patient rated severity of illness at day $1,{ }^{12}$ whether the patient wanted antibiotics or not, clinicians' perception of patient
expectation for antibiotics, and clinicians perception that antibiotics would help the

Table 1. Symptoms and working diagnosis by antibiotic treatment

\begin{tabular}{|c|c|c|c|c|}
\hline & $\begin{array}{c}\text { No } \\
\text { antibiotics }\end{array}$ & $\begin{array}{l}\text { Immediate } \\
\text { antibioticsa }\end{array}$ & $\begin{array}{l}\text { Delayed } \\
\text { antibioticsa }\end{array}$ & Total $^{2}$ \\
\hline \multicolumn{5}{|l|}{ Symptom } \\
\hline Cough & $1587(99.8)$ & $1561(99.8)$ & $210(100)$ & 3358 (99.8) \\
\hline Phlegm production & $11112(70.0)$ & $18(84.3)$ & $162(77.5)$ & 592 (777.1) \\
\hline Shortness of breath & $709(44.6)$ & $08(58.1)$ & $103(49.3)$ & $720(51.2)$ \\
\hline Wheeze & $459(28.9)$ & $22(46.1)$ & $89(42.6)$ & 1270 (37.8) \\
\hline Coryza & $1046[65.81$ & $1050(67.2)$ & $144(68.9)$ & $2240(66.6)$ \\
\hline Fever & $637(40.3)$ & $934(59.7)$ & $136(65.1)$ & $1707(50.9)$ \\
\hline Chest pain & $608(3 \varepsilon)>2)-2$ & 8845 & $91(43.5)$ & $1483(44.1)$ \\
\hline Muscle aches & $762148<>20$ & $832(53.2)$ & $116(55.5)$ & $1710[50.9)$ \\
\hline Headache & $904(56.9)$ & $964(61.6)$ & $129(61.7)$ & $1997(59.4)$ \\
\hline Disturbed sleep & $999(62.9)$ & $979(62.6)$ & $137 !$ & $2115(62.9)$ \\
\hline Feeling generally unwell & $1194(75.2)$ & $28(84.9)$ & $176(84.2)$ & 2698 (80.3) $>3$ \\
\hline Interference with normal activities & $1052(66.3)$ & $1140(72.9)$ & $143(68.4)$ & 2335 (69.5) \\
\hline Confusion & 50 (3.1) & $75(4.8)$ & $10(4.8)$ & $135(4.0)$ \\
\hline Diarrhoea & $91(5.7)$ & $93(5.9)$ & $12(5.7)$ & $196(5.8)$ \\
\hline \multicolumn{5}{|l|}{ Working diagnosis } \\
\hline & $406(25.6)$ & & $91(44.6)$ & \\
\hline UR & $529(33.3)$ & $261(16.7)$ & $44(21.6)$ & $834(24.9)$ \\
\hline Asthma/COPD related & $97(6.1)$ & $106(6.8)$ & $13(6.4)$ & $216(6.4)$ \\
\hline Non- & $184(111.6)$ & $53(3.4)$ & $15(7.4)$ & $252(7.5)$ \\
\hline Viral/ot & 361 [ 2 & 49 (3. & $40(19.6)$ & $450 \mid[13.4)$ \\
\hline Pneumonia & $11(0.7)$ & $129(8.3)$ & $1(0.5)$ & $141(4.2)^{a}$ \\
\hline
\end{tabular}

patient get better quicker. No individual symptoms Iphlegm production, shortness of breath, wheeze, coryza, fever, chest pain, muscle aches, headache, disturbed sleep, feeling generally unwell, interference with normal activities, confusion, and diarrhoeal delayed antibitics at the univariate level and

\section{RESULTS}

Three hundred and eighty-seven GPs included 3398 eligible patients. Case report form (CRF) data from the index consultation was avallable for $3368(99 \%)$, diary data for $2714(80 \%)$ and both CRF and diary The symptoms and working diagnoses for those who had a CRF completed are given in Table

Of the 3368 with CRF data, 210 (6.3\%) were prescribed an antibiotic and asked to delay its use, $1566(46.5 \%)$ received an antibiotic prescription for immediate use, and 1592 the index consultation. At the network lics at the use of delayed prescribing varied from $0.2 \%$ of consultations (Barcelona) to $33.1 \%$ (Southampton). Only three networks Łódż Milan, and Southampton) used a delayed prescribing approach in more than $5 \%$ of consultations. The proportion of participants receiving delayed, immediate, and no antibiotic prescriptions in each network are

Advised delay period

prescribed delayed antibiotics the median advised delay period varied from 2 days (Balatonfüred, Barcelona, Cardiff, Helsinki, Mataro, Rotenburg) to 7 days (Southampton, Utrecht) (Table 3). Only $22 \%$ of participants wee advised

\section{Antibiotic consumption}

s who were prescribed delayed antibiotics 169 provided data on antibiotic consumption. Of these, 75 (44.4\%) consumed their delayed antibiotic, $18(10.7 \%)$ consumed an antibiotic other than the delayed antibiotic during the consume any antibiotics dering the study period. Therefore, $93(55.0 \%)$ participants consumed an antibiotic during the study period. In comparison, $924(71.5 \%)$ of those prescribed immediate antibiotics consumed an antibiotic during the study period. $50(29.6 \%)$ started taking their delayed antibiotics on the day that they

\section{Table 2. Immediate, delayed, and no antibiotic prescribing by} network

\begin{tabular}{|c|c|c|c|}
\hline \multirow[b]{2}{*}{ Network } & \multicolumn{3}{|c|}{ Proportion (\%) } \\
\hline & Delayed antibiotics & Immediate antibiotics & No antibiotics \\
\hline Antwerp & 9/216 (4.2) & 47/216 (21.8) & 160/216 (74.1) \\
\hline Balatonfüred & $31 / 323(9.6)$ & 210/323 (65.0) & $82 / 323(25.4)$ \\
\hline Barcelona & $2 / 277(0.2)$ & $55 / 277(19.9)$ & 220/277 (79.4) \\
\hline Bratislava & $11 / 299(3.7)$ & 251/299 (83.9) & $37 / 299(12.4)$ \\
\hline Cardiff & $10 / 300(3.3)$ & 199/300 (66.3) & 91/300 (30.3) \\
\hline Helsinki & $5 / 103(4.9)$ & 38/103 (36.9) & 60/103 (58.3) \\
\hline Jönköping & $8 / 300(2.7)$ & 106/300 (35.3) & 186/300 (62.0) \\
\hline tódź & 27/301 (9.0) & 188/301 (62.5) & 86/301 (28.6) \\
\hline Mataró & 5/196 (2.6) & $62 / 196(31.6)$ & 129/196 (65.8) \\
\hline Milan & 21/207 (10.1) & 134/207 (64.7) & 52/207 (25.1) \\
\hline Rotenburg & 3/229 (1.3) & $76 / 229(33.2)$ & 150/229 (65.5) \\
\hline Southampton & $71 / 214(33.1)$ & 63/214 (29.4) & 80/214 (37.4) \\
\hline Tromsø & 4/203 (2.0) & $57 / 203(28.1)$ & 142/203 (70.0) \\
\hline Utrecht & $3 / 200(1.5)$ & 80/200 (40.0) & 117/200 (58.5) \\
\hline OVERALL & $210 / 3368(6.3)$ & 1566/3368 (46.5) & $1592 / 3368(47.6)$ \\
\hline
\end{tabular}

by network for patients given a delayed prescription is illustrated in Figure 2

Factors associated with consumption of the delayed antibiotic prescription

No individual symptoms were associated with consumption at a univariate level and therefore none were included in the regression analysis. 150 participants had data on consumption of their delayed antibiotic prescription and data for al

\section{Table 3. Duration of delay advised by networks}

\begin{tabular}{|c|c|c|}
\hline Network & $\begin{array}{l}\text { Duration of delay, days, } \\
\text { median (IQR) }\end{array}$ & $\begin{array}{c}\text { Advised a delay of at least } 7 \text { days, } \\
\text { proportion }(\%)\end{array}$ \\
\hline Antwerp & $3(2.5-7)$ & $3 / 8(37.5)$ \\
\hline Balatonfüred & $2(2-3)$ & $0 / 31(0.0)$ \\
\hline Barcelona & $2(2-2)$ & $0 / 2(0.0)$ \\
\hline Bratislava & $3(2-3)$ & $0 / 11(0.0)$ \\
\hline Cardiff & $2(2-2)$ & 0/10 (0.0) \\
\hline Helsinki & $2(2-2)$ & $0 / 5(0.0)$ \\
\hline Jönköping & $2.5(2-3.5)$ & $1 / 8(12.5)$ \\
\hline tódż & $3(2-3)$ & 1/27 (3.7) \\
\hline Mataró & $2(2-4)$ & $0 / 5(0.0)$ \\
\hline Milan & $3(2-3)$ & $2 / 21(9.5)$ \\
\hline Rotenburg & $2(1.5-2)$ & $0 / 3(0.0)$ \\
\hline Southampton & $7(4-8.5)$ & $37 / 71(52.1)$ \\
\hline Tromsø & $3(2.5-3)$ & $0 / 4(0.0)$ \\
\hline Utrecht & $7(5.5-7)$ & $2 / 3166.71$ \\
\hline OVERALL & $3(2-5)$ & $46 / 209(22.0)$ \\
\hline
\end{tabular}

included covariables (Figure 1). Having a working diagnosis of 'upper respiratory tract infection, non-specific respiratory tract infection' or viral / other illness' was associated with a reduction in the odds of consuming a delayed antibiotic prescription chabracteristics, patient illness, duration of advised delay and the clinicians views on the likely benefit from antibiotics, patients who wanted an antibiotic had increased odds of consuming their prescribed antibiotic $(O R=2.51,95 \% \mathrm{Cl}=1.06$ to 5.90, $P=0.035)$ and clinician's perception that the patient wanted them to prescribe odds of consuming them (OR $=038.95 \% \mathrm{Cl}$ $=0.15$ to $1.00, P=0.050$ ) (Table 4).

\section{DISCUSSION}

Summary

In this observational study of adults presenting with acute cough, delayed prescribing was used in the minority large variation between, networks in the frequency with which this approach was used. The median advised delay period was 3 days, with a median advised delay of $\geq 7$ days in only two of the networks. Over half $(54.4 \%)$ of those prescribed delayed antibiotics took an antibiotic at some point in the 4-week follow-up period, and nearly half $(44.4 \%)$ took the antibiotic prescribed those who took their delayed prescription started it on the day it was prescribed. Patients with a working diagnosis of upper respiratory tract infection (URTI), viral infection or non-specific infection were less likely to consume their delayed antibiotic prescription. Patient's who indicated that they wanted an antibiotic were more likely patients whose clinician had a perception that they wanted antibiotics were less likely to consume them.

Strengths and limitations The study described routine care in 14 networks in 13 European countries. The patient eligibility criteria were broad and patients were not randomised. Data on routine prescribing behaviour in everyday
clinical practicecan onlybeobtained through observational data. The nature of this study. with clinicians asked to record their usual practice, and patients asked to record their behaviours prospectively, meant that these results are likely to reflect routine care in these practices. The multinational nature of
the study also increases the generalisability 


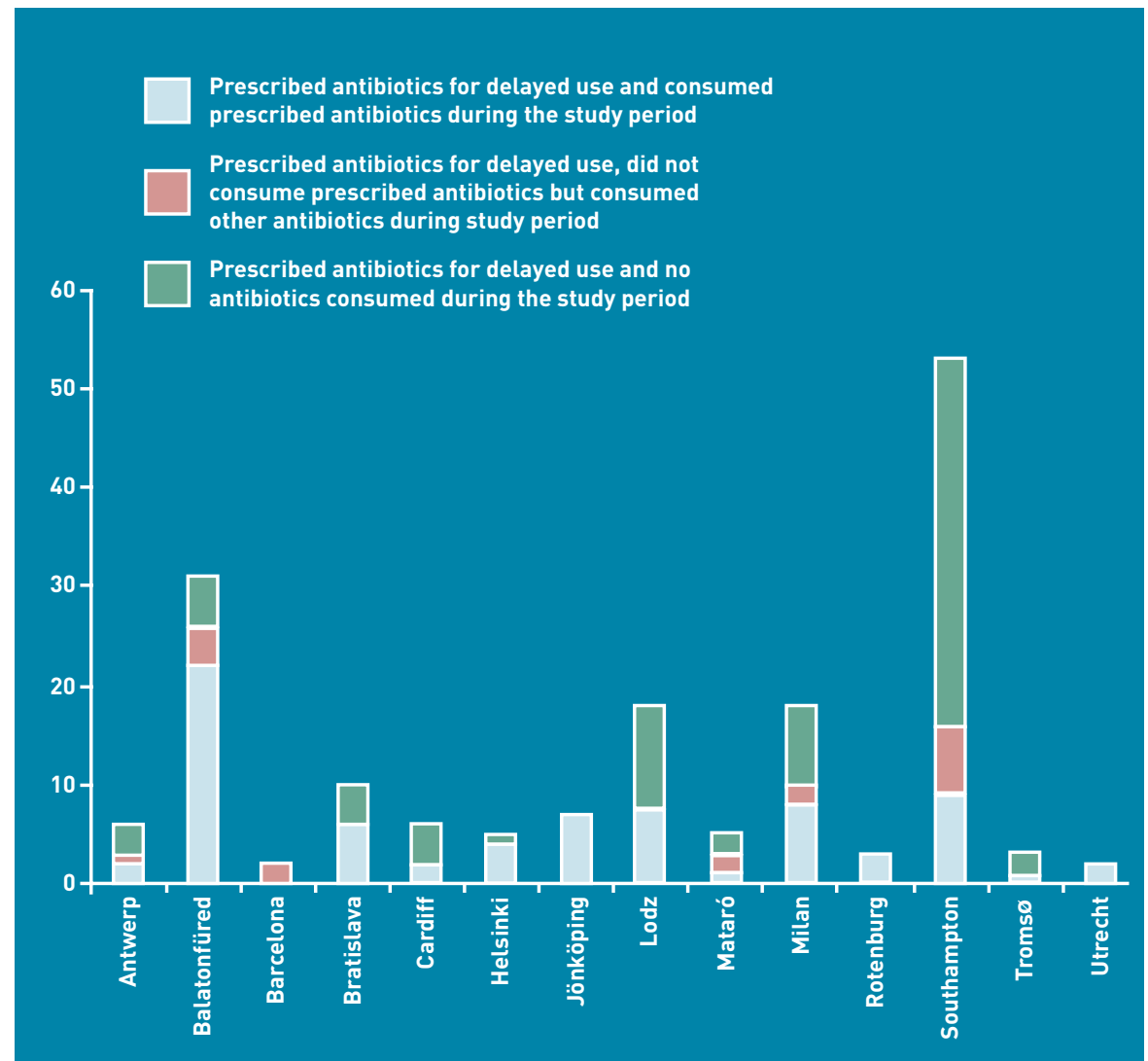
Figure 2 . Antibiotic consumption by network for
265 patients prescribed delayed antibititics. of the results and allows for comparisons between countries.

Although clinicians were asked to record the use of the delayed prescribing strategy. there are no data on what was actually said to patients in consultations, and it is either overtly or subtly, delaying use of the antibiotics but did not record this advice. As delayed prescribing was used in a minority of cases, the study may not have sufficien power to clearly describe the association of some factors with consumption of a delaye antibiotic. Furthermore, the use of a delayed prescribing approach was dominated by lew networks with only the Southampton and Milan networks using the strategy Southampton and Balatonfüred networks with 30 or more patients who had received a delayed prescription. Therefore, the results of the regression model may reflect local factors. For the same reason, the description of how frequently the strategy was used and the median advised delay has timited precision in networks approach was used infrequently.
Comparison with existing literature Despite delayed prescribing being widely
researched since the late 1990s, and recommended in National Institute for Health and Clinical Excellence (NICE) guidance on antibiotic prescribing for respiratory tract infections in the UK, ${ }^{2}$ little is known about how requently this strategy
is used in conditions of usual clinical care. This is largely because the advice to delay taking a prescription is generally not coded in general practice electronic records, and therefore not easily accessible in database studies." The data shows that delayed antibiotic prescribing has LRT throughout Europe. The aprough/ was used in approximately one-third of consultations in the English network (Southampton), and therefore may be used more extensively in England than the rest of Europe. However, this network is linked to a university department that led many locally recruiting studies of delayed prescribing, and therefore may delayed prescribing was used in only $33 \%$ of consultations. Sharland and colleagues compared data on prescribing with data on prescriptions issued by pharmacists in England and found evidence of a reduction in the proportion of antibiotic prescriptions taken to pharmacists during the late 1990s and early 2000s following the publication They hypothesised that this was explained by uptake of delayed prescribing and suggested that at least in the UK use of the approach is likely to be widespread. An observational study of 273 patients with respiratory tract infections presenting in general practices in Germany found that delayed prescribing was not used at all. ${ }^{18}$ This study's data therefore describe the strategy across Europe. Possible explanations

Posste ex luraption for the apparent acute cough across Europe include a lack of Inclusion in many national guidelines, a lack of awareness of the strategy and concerns about the approach among primary care clicians and/or palients. A of primary care clinicians in the UK found low reported use of delayed prescribing and concerns about sending out conflicting messages and altering the locus of control from the clinician to the patient.19 However, the latter study provided no detals about how clinicians conceived of/operationalised
Table 4. Association between patient/clinical characteristics and consumption of a delayed antibiotic in 150 patients who consulted with 66 clinicians with LRTI and were issued with a delayed

prescription

Variable

Odds ratio

$95 \% \mathrm{Cl} \quad P$-value

Patient characteristics
Age (decades)

Age (decades)
Sex: Female (Ref)

No comorbidities (Ref)

At least one comorbid

Employed Ret
Not employed
Pats

Patient illness informatio

$\begin{array}{llll} & 0.13 & 0.78 \text { to } 1.64 & 0.545\end{array}$

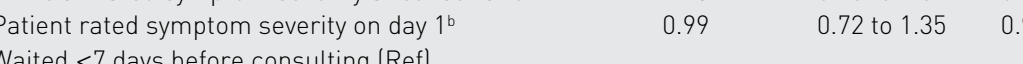

Waited 27 days before consulting

Clinician working diagnosis

Lower respiratorytract infection (Ref)

Asthma/COPD-related illness

Non-specific respiratory tract infection

Villother illness

Duration of advised delay

$<7$ days

Patient behavio

Palient did not want antibiotics IRen

Patient wanted antibiotics

Clinician perception 'This pat

Cinician does not agree $(\mathbb{R}$ en
Cinician agrees

(Clinician perception: 'Antibios not agree $R$ (Res

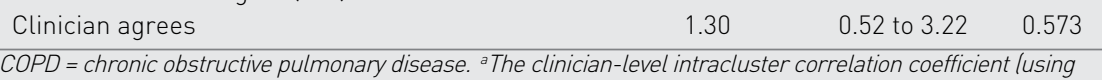

the standard n $2 / 3$ estimatorl was 0.10 . boR for a 10 percentage point increase

contrast to the trial evidence, wher the change in beliess and behaviour are New Zealand, that also explored the views of patients, found considerable variation in reported use and opinions about the strategy. ${ }^{20}$ Some patients reported feeling uncomfortable about being given the decision about when to use antibiotics, and others reported taking delayed antibiotics immediately. Some clinicians thought that the strategy helped empower patients, their expectations, while others expressed concerns about patients using them nappropriately, about masking serious illness, and about medicolegal problems. The study found that just under half of the patients given a delayed prescription took them; a proportion that is higher than in
trials of this approach 4.6 The results are not dissimilar to observational studies of this in the US, where $31 \%$ consumed a delayed prescription, and patients with upper respiratory tract infections (URT) in southeast England, where 53.1\% consumed their delayed antibiotics." However, both of these group of practices and therefore the results probably provide more accurate data on use in everyday practice.

The finding that two-thirds of those who consumed their delayed prescription did not adhere to any delay (started their antibiotics on the day they were prescribed) is in antibiotics immediately in a study of URT 22 $^{22}$ However, this is consistent with the finding that URTI was associated with reduced odds of consuming a delayed antibiotic prescription compared with LRTI. Only nine of the $53(17.0 \%)$ patients who received a delayed prescription in Souhampton consumed their delayed prescription. Many participated in trials of delay prescribing so this may reflect the benefit of having taken part in these trials or the effects of local opinion leaders.

In trials of delayed prescribing clinicians are usually instructed to use the approach as part of a package that includes; il advice about the (limited) effectiveness and disadvantages of using antibiotics for
their illness, and iil advice about the likely time-course of their symptoms and how to decided when to take the antibiotic. RTI symptoms commonly last longer than patients expect, and therefore advice about how long to delay the prescription is an important element of this package. Inadequate provision of advice, or provision of inaccurate or inappropriate advice, are reported consumption found in trials of this approach and in this study In particular. the duration of delay advised by clinicians in this study was considerably shorter than the 1 to 2 weeks used in the trials and recommended in guidelines ${ }^{4,6}$ The study did not find a significant association between a longer delay and lower consumption. the direction of such an assocition, and a lack of association may have been a Type II error. The study has no data concerning the advice given by clinicians when a delayed prescription was used. However, given the poor adherence of clinicians to the advice about duration of delay, it seems likely that other elements of the delayed prescribing 
the limited effectiveness of antibiotics,
their disadvantages, and when to consider using the antibiotics) were also poorly adhered to, which is tikely to undermine th effectiveness of the strategy.

The melhod of delvering the delayed prescription to the patient may also have used. Consumption of delayed antibiotics is likely to be lower if it is left up to the patients to collect the prescription at a later point rather than being given to the patient durin the consultation. There is no data for this study concerning the method of providing the delayed prescription employed. Th patient wanted an antibiptic was associated with less consumption may seem at odd with the finding that patient's express hope for antibiotics was associated with greater consumption. The most likely explanation is that clinicians would be more likely to discourage use of the delayed prescription when they had opled for a delayed lrather thought that the patient wated to take antibiotics.

\section{Implications for practice and research}

Delayed prescribing has been shown to be an effective approach to reducing antibiotic prescribing for acule cough in clinical trials ow in Europe, and is therefore currently likely to be having little overall effect on antibiotic consumption. Indeed the finding that twohirds of those who consumed antibiotics prescribed in their delayed prescription did so on the day it was prescribed suggests delayed prescribing strategy or a degree of resistance among patients to adopt this pproach. Opinion leaders may be able to play a role in increasing awareness about the need for clear communication as part of any delayed prescribing package. Further studies can be used to explore the barriers and opportunities for improving how the various components of the delay prescribing 'package' affect uptake of the approach and subsequent consumption of antibiotics. Two elements that deserve further clarification are the acceptability and effect of varying the advised delay period, and effect of different methods of delivery an antibiotic consumption and patien of the views and behaviours of clinicians and patients around use of this approach is needed: for example, whether clinicians and patients feel happy with advice to delay antibiotics by $1-2$ weeks, and what advice they give patients about when to use their prescription (symptoms not resolved, not getting better, getting worse) and about

\section{REFERENCES}

Smith SM, Fahey T, Smucny, etal. An
Database Syst Rev 2004; $44:$ : CD00024

National Institute for Heath and Clinical Excellence. Prescribing of antibiotics

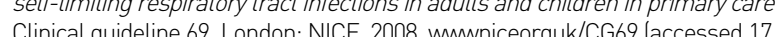
2012! 3. Little P. Delayed prescribing of antibiotics for upper respiratory tract infection.
$B M 2$ 2005; 33177512): 301-302.

4. Little P, Rumsby K, Kelly $\mathrm{J}$, etal. Information leaflet and antibiotic prescribing strategies for acute lower respirator
trial. JAMA $2005 ;$; $2932424: 3029-3035$

5. Cates C. Delayed prescriptions in primary care. Br J Gen Pract 2003: 53/496), 836-837

6. Dowell J, Pitkethly M, Bain J, Martin S. A randomised controlled trial of delayed antibiotic prescribing as a strategy for managing uncomplicated respiratory tract

Little P, Gould C, Williamson IG, etal Pragmatic randomised controlled trial
of two prescribing strategies for childhood acute otitis media. BMJ 2001;

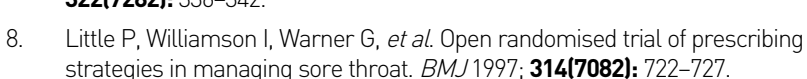

9. Spurling GKP, Del Mar CB, Dooley LLF Foxlee R. Delayed antibiotics for symptoms (2): CD004417.

10. Sharland $\mathrm{M}$, Kendall $\mathrm{H}$, Yeates $\mathrm{D}$, et al. Antibiotic prescribing in general practic

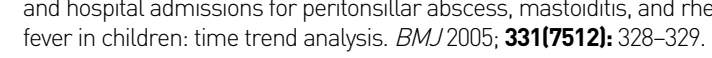

11. Butler CC, Kelly MJ, Hood K, et al. Antibiotic prescribing for discoloured
soutum in acute cough/lower respiratory tract infection. Eur Respir J2011: s8(1): 119-125.

12. Butler CC. Hood K Verheij TJ, et al Variation in antibiotic prescribing and its impact on recovery in patients with acute co
study in 13 countries. BMJ 2009; 338 : 22242 . study in 13 European countries. Eur Resoir J2010; 35(4): 761-767.

14. Jakobsen KA, Melbye H, Kelly MJ, et al. Influence of CRP testing and clinical
findings on antibiotic prescribing in adults presenting with acute cough in

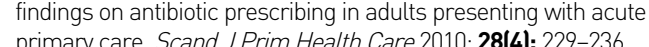

15. Butter CC, Hood K, Kelly MJ, etal. Treatment of acute cough/lower respiratorn Butler CC, Hood KK Kelly MJ, etal. Treatment of acute coughhlower respirat
tract infection by antibiotic class and associated outcomes: 13 European country observational study in primary care. J Antimicrob Chemother 2010.
$65(11): 2472-2478$

16. Wood JJ Butter $\mathrm{CC}$, Hood $\mathrm{K}$, et al Antibibitic prescribing for adults with acute
coughh/lower respiratory tract infection: congruence with uuidelines. Eur Respir J 2011; 38(1): :12-118.

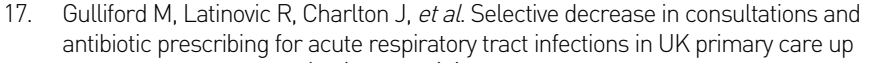
antbiotic prescribing for acute respiratory tract
to 2006 . J Public Health $(0 x f)$ 2009; 3144$): 512-520$

18. Fischer T. Fischer S, Kochen MM. Hummers Prodier Elnftwence of patient

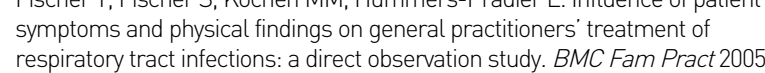
6(1): 6

19. Peters S, Rowbotham S, Chisholm A, et al. Managing self-limiting respiriatory

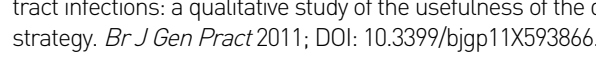

20. Arroll B, Goodyear-Smith F, Thomas DR, Kerse N. Delayed antibiotic

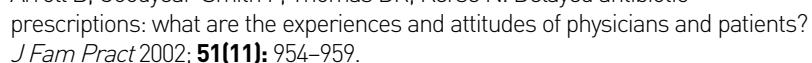

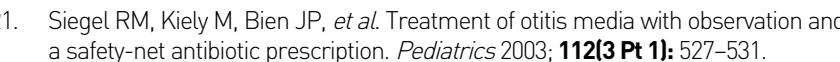
22. Edwards M, Dennison J, Sedgwick P. Patients' responses to delayed antibiotic
prescripition for accute upper respiratory tract infections. Br J Gen Pract 2003;
This study was funded by 6th Framework Programme of the European Commission
(LSHM-CT-2005-518226). The South East Wales Trials Unit and the Wales School of Primary Care Research are funded by the National Institute for Social Care and Health Research. In Flanders (Belgium) this work was supported by the Research Foundation-Flanders (G.0274.08)

Ethical approval

Ethical approval was obtained from ethics committees in all participating countries.

Provenance

Freely submitted; externally peer reviewed.

Competing interests

The authors have declared no competing interests.

Acknowledgements

We would like to thank all patients, clinicians, and networks who participated the entire GRACE team for their expertise, hard work, and enthusiasm.

Discuss this article

Contribute and read comments about http.//wwwrcaporguk/bigp-discuss 